Check for updates

Cite this: RSC Adv., 2019, 9, 27904

\title{
Nepenthes-inspired multifunctional nanoblades with mechanical bactericidal, self-cleaning and insect anti-adhesive characteristics $\dagger$
}

\author{
Yuan Xie, (D) a Jinyang Li, (D) ${ }^{* a}$ Daqin Bu, ${ }^{a}$ Xuedong Xie, ${ }^{a}$ Xiaolong He, ${ }^{b}$ Li Wang ${ }^{\star c}$ \\ and Zuowan Zhou (D)
}

\begin{abstract}
In order to reduce the widespread threat of bacterial pathogen diseases, mechanical bactericidal surfaces have been widely reported. However, few of these nanostructured surfaces were investigated from a sustainable perspective. In this study, we have prepared, inspired by the slippery zone of Nepenthes, a multifunctional nanostructured surface with mechanical bactericidal, self-cleaning and insect antiadhesive characteristics. First, a nanoblade-like surface made of $\mathrm{Zn}-\mathrm{Al}$ layered double hydroxides was prepared for achieving faster bactericidal rate and wider bactericidal spectrum $\left(2.10 \times 10^{4} \mathrm{CFU}\right.$ $\mathrm{cm}^{-2} \mathrm{~min}^{-1}$ against Escherichia coli and $1.78 \times 10^{3} \mathrm{CFU} \mathrm{cm} \mathrm{cm}^{-1} \mathrm{~min}^{-1}$ against Staphylococcus aureus). Then the self-cleaning and insect anti-adhesive properties were tested on the fluorosilane-modified nanoblades, leaving little cell debris remaining on the surface even after 4 continuous bactericidal experiments, and showing a slippery surface for ants to slide down in $3 \mathrm{~s}$. This study not only discovers a new nature-inspired mechanical bactericidal nanotopography, but also provides a facile approach to incorporate multiple functions into the nanostructured surface for practical antibacterial applications.
\end{abstract}

Received 8th July 2019

Accepted 24th August 2019

DOI: $10.1039 / \mathrm{c} 9 \mathrm{ra} 05198 \mathrm{~h}$

rsc.li/rsc-advances morphology of nanorod array and bactericidal performance, ${ }^{13,21,22}$ and the study of the physical bactericidal mechanism. ${ }^{23,24}$ However, the impact of the cell debris left on the mechanical bactericidal surface has yet been investigated systematically, from the perspective of a sustainable and effective antibacterial surfaces. ${ }^{20}$ In fact, cell debris will accumulate continuously on the surface along with the progress of the sterilization process, which affects the effective contact between bacteria and bactericidal nanostructures and reduces the bactericidal performance. ${ }^{21}$ In addition, since cellular debris can also contaminate surfaces and serves as a source of nutrients for living bacteria cells, ${ }^{25}$ it is essential to quickly and effectively remove the cell debris from the protected surfaces. Among the few studies involving the removal of cellular debris, none of them applies the mechano-responsive bactericidal mechanism, but they either rely on the deformation of smart materials or photocatalysis to remove the cellular debris. ${ }^{26-28}$ Besides, these methods need extra help such as light sources for photocatalysis ${ }^{28}$ or specific stimuli for smart materials ${ }^{26,27,29}$ that are not that convenient in practical applications, which leaves the question mark for whether there is a simple approach to remove the cell debris from the bactericidal nanostructured surfaces.

Fortunately, nature provides the answer. Nepenthes pitcher plant has been well studied for its slippery surface. ${ }^{30-33}$ The existing researches on surface lubrication of Nepenthes pitcher mainly include two aspects. (1) The microstructure with radial ridges on the pitcher rim (peristome) can realize the selftransport of liquid and form a film on the surface. ${ }^{34}$ Thus, insect "aquaplaning effect" is achieved..$^{30}$ Ultra-slippery coatings 
with a similar principle of low surface functionalization of lubricants have been artificially imitated..$^{35}$ On this basis, Joanna Aizenberg et al. report that using lubricants effectively prevents bacteria from adhering and growing on substrate..$^{36,37}$ Lynn's group further selected lubricants with bactericidal activity that confer bactericidal properties on surfaces. ${ }^{38}$ The surface nanostructure plays the dual functions of maintaining and releasing the lubricant at the same time, which helps to realize the long-term sterilization of the surface. However, the bactericidal properties of the surface are still achieved by chemical fungicides, which can still cause problems such as drug resistance. (2) The lubrication of insect feet against the epicuticular wax crystals on the slippery zone. ${ }^{39}$ However, these studies did not involve the interaction between the inner surface of pitcher plant and bacteria. In this study, we found the slippery zone possessing a weak but still effective mechanical bactericidal activity, which is yet reported in literature. Inspired by this idea, we report a multifunctional nanostructured surface with mechanical bactericidal, self-cleaning and insect antiadhesive characteristics, expecting to promote the development of mechanical bactericidal surfaces for practical and sustainable applications fighting against threats from pathogen and vector-borne diseases.

\section{Experimental section}

\section{Materials}

Aluminum alloy sheet (AAS, 5A06), pure ethanol and sodium carbonate $\left(\mathrm{Na}_{2} \mathrm{CO}_{3}\right)$ were purchased from Chang Zheng (Chengdu). Zinc nitrate hexahydrate $\left(\mathrm{Zn}\left(\mathrm{NO}_{3}\right)_{2} \cdot 6 \mathrm{H}_{2} \mathrm{O}\right)$ and hexamethylenetetramine (HMTA, $\left.\left(\mathrm{CH}_{2}\right)_{6} \mathrm{~N}_{4}\right)$ were purchased from Aladdin (Shanghai). All the chemicals used in this work were analytical grade. Deionized water was used as the hydrothermal growth solution.

\section{Preparation of pitcher plant sheets}

The pitcher plant Nepenthes alata specimens were purchased from San Sheng, a local flower market in Chengdu. The slippery zone sheets $(1 \mathrm{~cm} \times 1 \mathrm{~cm})$ were carefully cut out from Nepenthes alata pitchers. To fabricate collapsed natural nanoblade (CNNB) surfaces, NNB surfaces were covered with a cover glass and adding pressure by a counterweight (100 g) for $10 \mathrm{~min}$.

\section{Hydrothermal growth of ANBs}

The chemical bath deposition (CBD) was used to construct ZnAl layered double hydroxides NBs on AAS. A piece of AAS substrate $(1 \mathrm{~cm} \times 1 \mathrm{~cm})$ was first immersed into an $80 \mathrm{~mL}$ hydrothermal growth solution which contained $\mathrm{Na}_{2} \mathrm{CO}_{3}(1 \mathrm{~mL}$, $1 \mathrm{mM}$ ), and equimolar (40 mL, $10 \mathrm{mM}) \mathrm{Zn}\left(\mathrm{NO}_{3}\right)_{2} \cdot \mathrm{H}_{2} \mathrm{O}$ and HMTA in aqueous solution at 50,70 and $90{ }^{\circ} \mathrm{C}$ for $30 \mathrm{~min}$. Then the substrate was cleaned with ethanol and deionized water several times to remove any organic residue. To fabricate compacted artificial nanoblade (CANB) sheets, ANBs sheet were also covered with a cover glass and adding pressure by a counterweight $(100 \mathrm{~g})$ and compact for $10 \mathrm{~min}$.

\section{Characterization}

To characterize the ANBs surface topographies, field emission scanning electron microscopy (FE-SEM, JSM-7001F, JEOL) was used at a voltage of $20 \mathrm{kV}$. A nanoblade scraped from the substrate was characterized by transmission electron microscopy (TEM, JEM-2100, JEOL). X-ray diffraction patterns were recorded by an X-ray diffractometer (XRD, Philips X' Pert PRO), with $\mathrm{Cu} \mathrm{K} \alpha$ radiation $(\lambda=1.5418 \AA)$.

\section{Bactericidal properties of NNBs and ANBs}

The bactericidal properties of the wax NNBs and Zn-Al layered double hydroxides ANBs against Escherichia coli (E. coli) and Staphylococcus aureus (S. aureus) cells were evaluated using the sticking membrane method referring to the JIS Z 2801 (Japanese Industrial Standard). ${ }^{\mathbf{1 0 4 0}}$ Using this method, the selected bacterial suspension (E. coli strain [ATCC 25922] and $S$. aureus strain [ATCC 6538], purchased from Guang Dong Detection Center of Microbiology, China) was activated on an agar culture medium (AOBOX Co., Ltd. Beijing) overnight at $37{ }^{\circ} \mathrm{C}$ and proliferated in a nutrient broth medium at $37{ }^{\circ} \mathrm{C}$ for $3 \mathrm{~h}$. The bacterial cell suspension was then diluted by broth medium to proper concentration (NNBs: E. coli, $2.1 \times 10^{5} \mathrm{CFU} \mathrm{mL}^{-1}$ to 2.9 $\times 10^{5} \mathrm{CFU} \mathrm{mL}{ }^{-1}$; ANBs: E. coli, $2.2 \times 10^{6} \mathrm{CFU} \mathrm{mL}^{-1}$ to $2.9 \times 10^{6}$ CFU mL ${ }^{-1}$ and $S$. aureus, $1.3 \times 10^{5} \mathrm{CFU} \mathrm{mL}^{-1}$ to $2.6 \times 10^{5} \mathrm{CFU}$ $\mathrm{mL}^{-1}$ ) to afford a standardized suspension. All samples (slippery zone sheet, aluminum alloy sheet, ANBs sheets, ACNBs sheets and PE membrane) were cut into $1 \mathrm{~cm} \times 1 \mathrm{~cm}$ and immersed into $75 \%$ ethanol for $1 \mathrm{~min}$ and dried in an ultraclean cabinet prior to use. $100 \mu \mathrm{L}$ of standardized bacterial cell suspension was added onto each sample surface and incubated at $37{ }^{\circ} \mathrm{C}$ in dark for $10 \mathrm{~min}, 60 \mathrm{~min}$, and $120 \mathrm{~min}$, respectively. All the height of the drops is accuracy controlled to avoid the interference of initial droplet rate. Each sample was thoroughly washed with $1 \mathrm{~mL}$ sterilized physiological saline. The bacterial cell suspensions were subsequently diluted in sterile physiological saline for suited concentration. Cell counts were obtained by spreading $100 \mu \mathrm{L}$ of bacterial cell suspension onto agar plates. CFU on each agar plate were counted after incubation at $37{ }^{\circ} \mathrm{C}$ for $18 \mathrm{~h}$, and the number of CFU per $\mathrm{cm}^{2}$ was calculated. Each test is carried out in dark conditions and repeated five times.

\section{Interactions between bacterial cells and NBs}

The $E$. coli strain was activated on an agar culture medium at $37{ }^{\circ} \mathrm{C}$ overnight, followed by proliferation in $30 \mathrm{~mL}$ of nutrient broth medium at $37{ }^{\circ} \mathrm{C}$ for $3 \mathrm{~h} .100 \mu \mathrm{L}$ of bacterial suspension was then added onto each surface. After incubation for $10 \mathrm{~min}$, samples were fixed in $2.5 \%$ glutaraldehyde for $12 \mathrm{~h}$ at $4{ }^{\circ} \mathrm{C}$, followed by ethanol gradient dehydration. The samples were soaked for $15 \mathrm{~min}$ in each step. After drying overnight at room temperature, bacterial cell topographies were observed by FESEM.

In the self-cleaning experiment, each sample was washed by simulated rain $\left(20 \mu \mathrm{L} \mathrm{s}{ }^{-1}, 10 \mathrm{~s}\right)$ after 4 times bactericidal 
experiments. Then the SEM observation and the contact angle measurements were carried out.

\section{Bacterial cell integrity on NBs}

Confocal laser scanning microscope (CLSM 510 Meta laser scanning confocal microscope, Carl Zeiss) was used to observe bacterial cells on the NB surfaces. $E$. coli cells were stained with the fluorescent nucleic acid dye kit containing SYTO-9 and PI (LIVE/DEAD BacLight Bacterial Viability Kit, Invitrogen). Prior to microscopic observation, $1 \mathrm{~mL}$ of bacterial cell suspension was stained with $1.5 \mu \mathrm{L}$ of a PI and SYTO-9 mixture ( $1: 1, \mathrm{v} / \mathrm{v})$, followed by incubation for $15 \mathrm{~min}$. Then the testing samples were immersed into stained bacterial cell suspension and flat on the aseptic bench, followed by covering with a sterilized cover slip. After incubating for another $1 \mathrm{~min}$, the samples were observed under CLSM. All the steps were proceeded in dark at room temperature.

\section{Preparation of grafted-ANBs}

The HD-ANBs sheets were immersed into (heptadecafluoro1,1,2,2-tetrahydrodecyl) trimethoxy silane isopropanol solution $(1.5 \%, \mathrm{v} / \mathrm{v})$ for $10 \mathrm{~min}$. Then the samples were transferred to $60{ }^{\circ} \mathrm{C}$ oven for $5 \mathrm{~min}$. The grafted-ANBs were prepared.

\section{Insect anti-adhesive experiments}

To evaluate the insect anti-adhesive performance of NNB and ANB surface, insect resistant crawling experiments were adopted. Pheidole jucunda ants were utilized. For NNB surface, the slippery zone of Nepenthes alata were cut into proper size and wrapped around two test tubes. Five ants were placed into the bottom of the vertical device and watch their crawling behaviour within $3 \mathrm{~min}$. The number of the ants reaching the upper of the device was recorded. For ANB and grafted-ANB surfaces, the ants were placed on to tested sheets which were pre-placed at an inclination of $45^{\circ}$. Then the inclination of the sheets was gradually adjusted to $60^{\circ}$, the climbing performance of ants on the surface was observed in this process.

\section{Results and discussion}

\section{The mechanical bactericidal performance of natural} nanoblades

As a typical tropical insectivorous plant, Nepenthes pitcher plant grows in high temperature and humidity (annual average temperature: $25{ }^{\circ} \mathrm{C}, \mathrm{RH}>75 \%$ ). Because of its insect-catching properties, the traps often contain dead insect and digestive juices dissolved with small molecular nutrients. Therefore, the internal environment is very suitable for bacterial growth. These potential pathogen contamination factors all require that the pitchers have certain antibacterial properties. So first, we focus on the insect aquaplaning surface of the peristome, ${ }^{30,41}$ but the surface doesn't exhibit bactericidal performance (Fig. S1 $\dagger$ ). However, the slippery zone below the peristome inside pitches (Fig. 1a) is also slippery for successful trapping and shows bactericidal performance against $E$. coli (Fig. 1b). The CLSM also indicate the integrity of $E$. coli cells (shows red fluorescence)

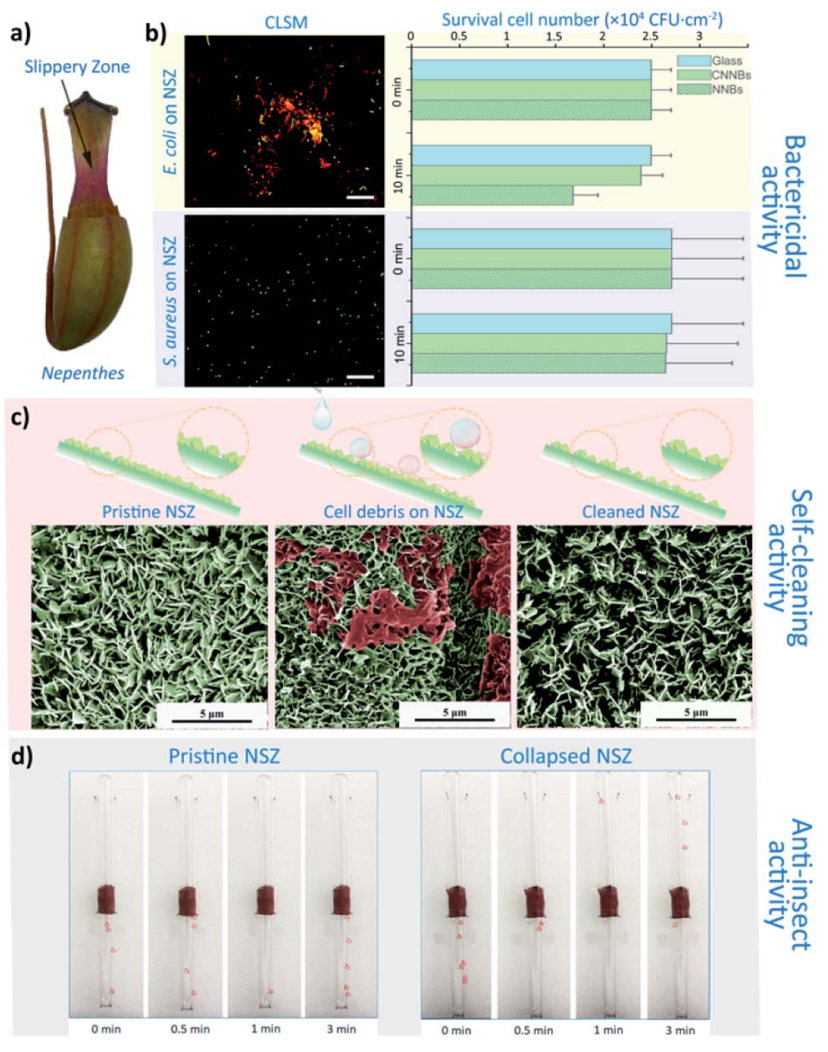

Fig. 1 The bactericidal activity, self-cleaning property and insect antiadhesion of Nepenthes slippery zone. (a) Pitcher of Nepenthes; (b) Confocal Laser Scanning Microscope (CLSM) images and bactericidal performance statistical results of $E$. coli and $S$. aureus on NSZ surface. The data are expressed as mean \pm S.D. of three replicates; (c) SEM images of pristine NSZ, E. coli debris on NSZ and contaminated NSZ surfaces after washing; (d) Pheidole jucunda ants climbing performance on NSZ and CNSZ surfaces within 3 min.

were destroyed by Nepenthes slippery zone (NSZ, Fig. 1b). As shown in Fig. 1c, NSZ surface is covered by numerous blade-like waxy crystals, ${ }^{\mathbf{4 2}}$ and these natural nanoblades (NNBs, average thickness: $78.4 \mathrm{~nm}$, density: $4.1 \times 10^{8}$ sheet per $\mathrm{cm}^{2}$ ) seems killing $E$. coli cells by tearing their cell membrane (Fig. S3c $\dagger$ ). Furthermore, a compacted natural nanoblades (CNNBs) were also adopted in bactericidal experiment as control (Fig. S3 $\dagger$ ). The $E$. coli cells are able to maintain their natural integrity on a flat CNNBs surface (Fig. S3b $\dagger$ ), which demonstrates that the nanostructures play an important role in the killing of bacteria, and the chemical composition of the NSZ has little effect on the bacteria. Besides, the production of reactive oxygen species (ROS) is also independent with bactericidal performance. Both of the $\mathrm{H}_{2} \mathrm{O}_{2}$ and $\cdot \mathrm{O}_{2}{ }^{-}$produced by NNBs and CNNBs were similar respectively under experimental conditions (Fig. S2a and $\mathrm{b}_{\dagger} \dagger$ ). Thus, the bactericidal activity of NNB surfaces is merely based on the mechanical bactericidal mechanism.

\section{The self-cleaning and insect anti-adhesive performance of natural nanoblades}

The NSZ surface also shows a good self-cleaning property against cell debris. As shown in Fig. 1c, the bacterial cell debris 
on the NSZ surface could be completely removed by a simple washing, mimicking the rain dropping in nature $\left(20 \mu \mathrm{L} \mathrm{s}^{-1}, 10\right.$ s). In this case, the NNBs can be re-exposed to ensure the bactericidal performance is sustainable. The insect antiadhesive experiment (Fig. 1d) could initially show that the NSZ surface were slippery to ant feet, for the ants were unable to crawl to the upper region of the apparatus within 3 minutes. This is due to the detachable property of the epicuticular wax crystals under the weight load of an insect foot. ${ }^{42}$ As mentioned above, the NSZ surface has the multifunctional properties of bacteria killing, self-cleaning and insect anti-adhesion.

Although NSZ has the desired multifunctional properties, there are three problems with the NNBs structure. First, the cell morphology as shown in Fig. S3f and $\mathrm{f}^{\prime} \dagger$ indicated that $S$. aureus cells could maintain their integrity on NNBs surface, which suggests NNBs have no bactericidal effect on $S$. aureus. The bactericidal experiments show a narrow bactericidal spectrum (Fig. 1b), this may due to the higher tip-width of the NNBs. Second, after the self-cleaning experiment, the density of NNBs decreased, which indicates that the wax crystals are brittle and low mechanical properties (Fig. 1c). Third, there are studies showing that both of the NNBs and lunate cells of NSZ play major role in insects attachment. ${ }^{39,43}$ In other words, due to the anisotropic structure and distribution of the lunate cells, the insect attachment efficiency is also greatly affected by the orientation of the Nepenthes alata pitchers. And the brittle wax crystals also impact the sustainable insect anti-adhesive function. These problems heavily affect the practical application for insect control and bactericidal purposes.

\section{Preparation and characterization of artificial nanoblades}

To address the weak mechanical strength of NNBs and to achieve superior mechanical bactericidal performance for higher bactericidal activity and wider bactericidal spectrum, we adopted a simple hydrothermal method to fabricate the artificial nanoblades (ANBs). We designed the ANBs so as to inherit and advance the merits of NSZ from three aspects: bactericidal activity, self-cleaning and insect anti-adhesion to prevent the carried pathogens, the cell debris and the insect vectors. By optimizing the hydrothermal growth conditions and growth time, a series of ANBs with different density were prepared, namely low density ANBs, medium density ANBs and high density ANBs (LD-ANBs, MD-ANBs and HD-ANBs, Fig. S4a-d $\dagger$ ). The ANBs topography statistical results were shown in Fig. S4e and $f, \uparrow$ suggests a successful imitation of natural nanoblade structure. HD-ANBs had minimum average blade width $(29.3 \pm$ $5.7 \mathrm{~nm})$ and highest density $\left(4.4 \pm 0.2 \times 10^{9}\right.$ slice per $\left.\mathrm{cm}^{2}\right)$. The degradation rate of HMTA increases as reaction temperature increases. Therefore, under high temperature, a mass of precursor was generated and participate reaction in initial reaction system. Thereby the growth rate of ANBs was higher and resulted in thicker ANBs. In addition, many ANBs crystals were combined during growth process, caused density decrease (Fig. S4b $\dagger$ ). With the increase of growth temperature, the height of ANBs also increased Fig. S4b. $\uparrow$ Thus, thicker and low density ANBs were obtained under higher growth temperature.
According to the density, the ANBs were intitule as high density ANBs (HD-ANBs, Fig. 2b, Fig. S4d $\dagger$ ), medium density ANBs (MDANBs, Fig. S4c $\dagger$ ) and low density ANBs (LD-ANBs, Fig. S4b $\dagger$ ). Structure of ANBs was characterized by X-ray diffraction (XRD). The patterns of the XRD show diffraction peaks at $11.6^{\circ}$ and $23.4^{\circ}$ to (003) and (006) planes respectively, clearly showing the formation of the $h c p \mathrm{LDH}$ phase. ${ }^{44}$ The peak at $23.4^{\circ}$ is probably due to the presence of $\mathrm{CO}_{3}-\mathrm{LDH}$, which were indexed to a typical $\mathrm{Zn}-\mathrm{Al}$ layered double hydroxide $\left(\mathrm{Zn}_{6} \mathrm{Al}_{2}(\mathrm{OH})_{16} \mathrm{CO}_{3} \cdot 4 \mathrm{H}_{2} \mathrm{O}\right.$, JCPDS card, no. 038-0486) structure (Fig. S5a $\dagger$ ). ${ }^{45}$ The structure of LDHs was further characterized by TEM. After scraped from the substrate and ultrasonicated in ethanol, the sheet-like nanoblades were also observed (Fig. S5b †). EDS spectrum (Fig. S5c $\dagger$ ) showed that the nanoblades were mainly composed of zinc, aluminium, and oxygen elements, indicating Al from the AAS participated in the growth of nanoblades under the hydrothermal conditions.

\section{The bactericidal performance of artificial nanoblades}

The interaction of ANBs with bacteria cells were shown in Fig. 2b-e. There is a significant correlation between the extent of cell destruction and the tip-width of the ANBs. The E. coli and $S$. aureus cell keeps their integrity shape and shows green fluorescence on LD-ANBs and AAS, which indicates the surface have no lethal effect against these two bacteria. However, cell debris was found on the thinner ANB surface, where the integrity of cell debris was negatively correlated with tip-width. Bactericidal experiments were also carried out to evaluate the ANBs bactericidal properties. A trend between the density and thickness of the ANBs and bactericidal results was observed (Fig. 2f, $g$ and S6 $\dagger$ ). With the decrease of blade thickness and the

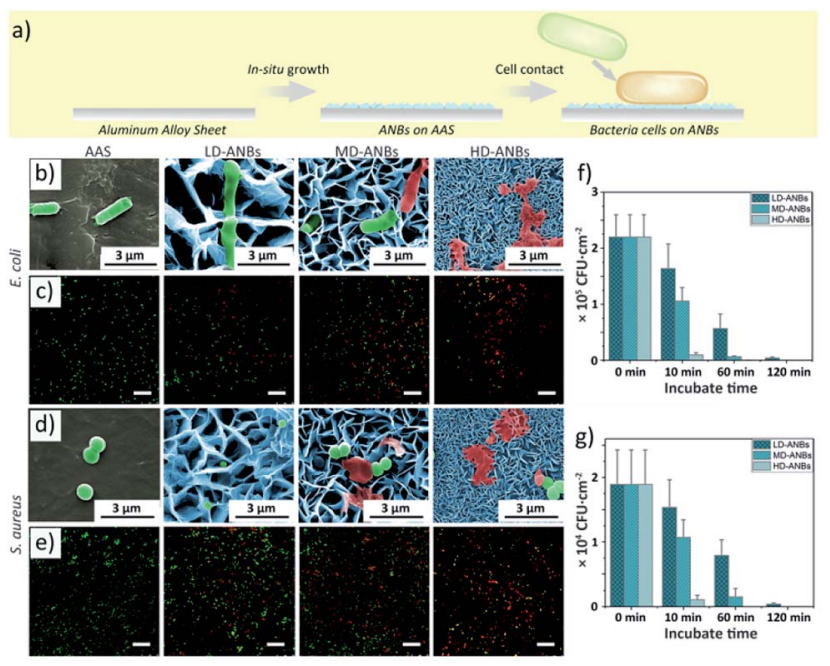

Fig. 2 The mechanical bactericidal activity of ANBs. (a) Schematic diagram of ANBs construction and in contact with bacteria; $(b-e)$ interaction of $E$. coli and $S$. aureus cells with ANBs observed by SEM and CLSM, contact time: $10 \mathrm{~min}$. ( $\mathrm{f}$ and $\mathrm{g}$ ) The bactericidal experiment statistical results of $E$. coli and $S$. aureus on ANBs surface. The data are expressed as mean \pm S.D. of three replicates. Scale bar $25 \mu \mathrm{m}$. 
increase of array density, the bactericidal performance of the surface increases. The tip-width of the nano-blade determines its efficiency in puncturing bacterial cells, while the NBs density determines the number of damage sites of a single bacterial cell. The HD-ANBs with thinner tip-width shows a fastest bactericidal rate $\left(2.10 \pm 0.36 \times 10^{4} \mathrm{CFU} \mathrm{cm} \mathrm{cm}^{-2} \mathrm{~min}^{-1}\right.$ against $E$. coli and $1.78 \pm 0.47 \times 10^{3} \mathrm{CFU} \mathrm{cm}{ }^{-2} \mathrm{~min}^{-1}$ against $S$. aureus) and a wider bactericidal spectrum (against both of two bacteria) within 10 min contact. Such a simple method could imitate and surpass the bactericidal performance of NNBs. To the best of our knowledge, the ROS and $\mathrm{Zn}^{2+}$ from ANBs may also contribute to the bactericidal properties. However, in the yield statistics of $\cdot \mathrm{OH}, \cdot \mathrm{O}_{2}{ }^{-}$and $\mathrm{Zn}^{2+}$, no obvious differences among three ANBs samples could be observed (Fig. S7 and Table S1 $\dagger$ ). That is, the bactericidal activity of the ANBs is also independent of the chemical product or composition. The results of bactericidal research of $\mathrm{ZnAl} \mathrm{LDHs} \mathrm{showed} \mathrm{that} \mathrm{the} \mathrm{compound} \mathrm{did}$ not have any bactericidal properties. ${ }^{46}$ Besides, related reports on the waterborne polyurethane surface filled with $1 \mathrm{wt} \% \mathrm{ZnAl}$ LDHs of sterilization performance can kill $2.64 \times 10^{4}$ bacteria within $24 \mathrm{~h}^{{ }^{47}}$ The bactericidal rate is much lower than NBs surface, therefore, it can be inferred that even though $\mathrm{ZnAl}$ LDHs has bactericidal property, it does not have obvious effect during the experimental period (10 min).

\section{The self-cleaning and insect anti- adhesive performance of the artificial nanoblades}

Since the physical bactericidal properties are based on the direct contact between bacteria and cell debris will form accordingly on ANBs, a continuous bactericidal experiment was carried out in order to evaluate the impact of cell debris on ANBs. As shown in Fig. $3 \mathrm{~b}$ and c, cell debris was accumulated in the gaps of the ANBs after 4 times experiment, due to the higher surface energy. The effectiveness of surface bactericidal activity is also affected in a negative way (Fig. 3d and e), this may be attributed to the accumulation of bacterial debris on the surface which affects the morphology of nanoblade (Fig. $3 \mathrm{~b}$ and c). Due to the presence of hydrophilic compounds such as peptidoglycan and protein on the cell wall, same results were obtained in the water contact angle experiment. The surface of ANBs contaminated by the bacterial debris shows hydrophilic behaviour, with a lower contact angle of about $10-20^{\circ}$ (Fig. $3 \mathrm{~b}$ and c). In order to mimic the low surface energy of NSZ, the HDANBs was grafted with (heptadecafluoro-1,1,2,2tetrahydrodecyl) trimethoxy silane. The grafted HD-ANB surface has little cell debris remained on the surface after 4 times bactericidal experiments (Fig. $3 \mathrm{~b}$ and c), which indicates that the bacterial debris is difficult to adhere on the grafted HDANBs surface, and demonstrates a good self-cleaning property. Furthermore, because the tips of grafted-ANBs were kept exposed, the surface remains super hydrophobic (Fig. $3 \mathrm{~b}$ and c) and the bactericidal activity is consistently sustainable (Fig. 3d and e). Thus, the simulation of self-cleaning performance is a)
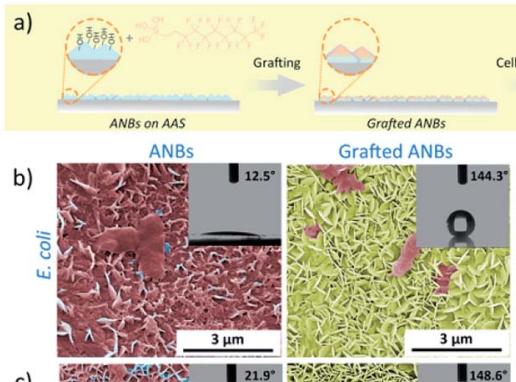

c)
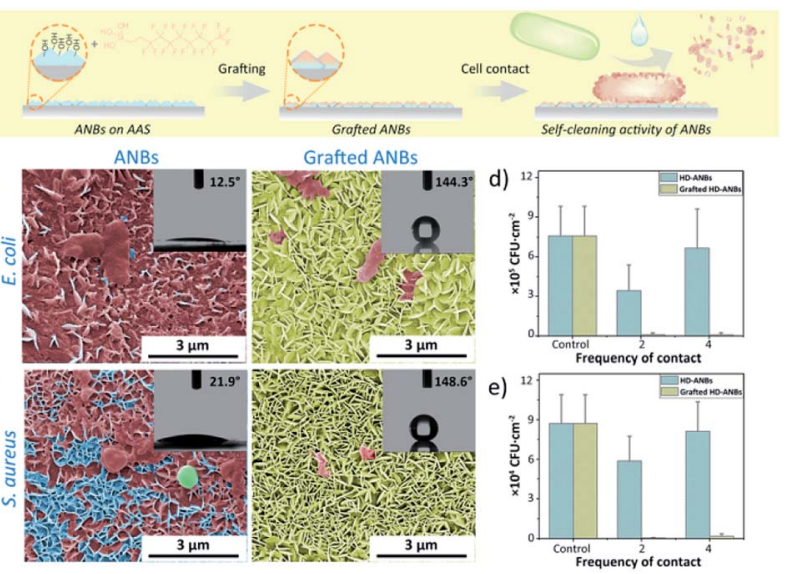

Fig. 3 The self-cleaning and sustainable bactericidal performance of grafted HD-ANBs. (a) Schematic diagram of ANBs grafting and selfcleaning of surface bacteria debris; ( $b$ and c) SEM images of HD-ANBs and grafted HD-ANBs contact with $E$. coli cells and $S$. aureus for 4 times continuously. ( $d$ and e) The bactericidal performance statistical results of $E$. coli and $S$. aureus on HD-ANBs and grafted HD-ANBs surface for 2 and 4 times. Contact time: $10 \mathrm{~min}$. The data are expressed as mean \pm S.D. of three replicates.

realized and the sustainable application of mechanical bactericidal performance is guaranteed.

In addition to the self-cleaning properties, surface fluorination can significantly increase the anti-climbing performance of the surface. The insect anti-adhesive experiment was also carried out and shown in Fig. 4 . The adhesive attachment of the ants, beetles and locusts (adhesive pads) achieve wet adhesion to surfaces through terminal secretion. ${ }^{48-52}$ According to the study of insect adhesion theory, insects show higher adhesion on smooth surfaces and lower adhesion on micro-rough surfaces than on nano-rough ones. ${ }^{53-55}$ So that the Pheidole jucunda ants can crawl freely on the smooth AAS surface (Fig. 4a). On HD-ANBs surface (tip-width $30 \mathrm{~nm}$ ), ants can stay on the same position for 20 seconds, indicating that the surface can prevent insects from crawling to some extent (Fig. 4b).

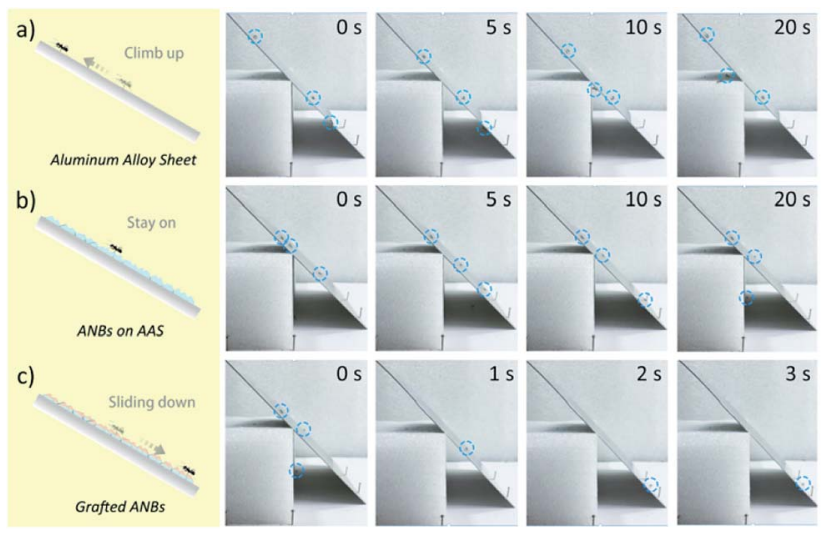

Fig. 4 The insect anti-adhesive performance of grafted ANBs. Pheidole jucunda ants crawling on (a) AAS, (b) HD-ANBs and (c) Grafted HD-ANBs. 
Therefore, we speculate that, the blade structure on the surface of ANBs could not only effectively reduce the contact area between the adhesive pad and the substrate, ${ }^{\mathbf{4 1 , 5 2 , 5 6}}$ but also the pore structure between the blades with high surface energy could quickly absorb the secretions of the adhesive pad, affecting the formation of effective adhesion between the ants feet and the surface. ${ }^{57}$ For grafted-ANBS surfaces, due to the low surface energy of the blade surface after fluorination, the adhesion pad exudates have difficulty in wet adhering the surface, which reduces the force of insect feet on the surface. In the meantime, because the ANBs surface does not have any micron level lunate cells, the anti-climbing performance of the surface shows isotropy. Therefore, as shown in Fig. 4c, it is difficult for ants to stay on grafted HD-ANBs surfaces, which slide off the surface in just three seconds. This indicates that the HD-ANBs is a premium insect anti-adhesive surface.

\section{Conclusions}

In summary, in order to prevent the accumulated bacterial debris affect to the mechano-bactericidal performance, we learn from nature. The mechanical bactericidal activity and selfcleaning performance of Nepenthes slippery zone was first found. Inspired by the pitcher plant, the bactericidal nanoblades structure was mimicked by using a simple hydrothermal method. Furthermore, compared with the NSZ surfaces, thinner, denser and higher mechanical properties nanoblades were prepared, with higher bactericidal rate and wider sterilization spectrum performance. After a simple fluorination treatment, the ANBs surface successfully mimic the selfcleaning and insect anti-adhesive performance of NSZ surface. Such multifunctional surface has a promising potential to be applied in sustainable applications avoiding the abuse of sterilizing agent, thereby not only inhibiting the pernicious environment pollution but also preventing high hazard vectorborne diseases.

\section{Conflicts of interest}

There are no conflicts to declare.

\section{Acknowledgements}

This work was financially supported by National Natural Science Foundation of China (No. 51772251), the Science and Technology Planning Project of Sichuan Province (No. 2017RZ0032 and No. 2018GZ0462), and the Fundamental Research Funds for the Central Universities (No. 2019XJ02).

\section{Notes and references}

1 Y. Yuan and Y. G. Zhang, Nanomed Nanotechnol, 2017, 13, 2199-2207.

2 K. Glinel, A. M. Jonas, T. Jouenne, J. Leprince, L. Galas and W. T. Huck, Bioconjugate Chem., 2009, 20, 71-77.

3 W. X. Lei, X. C. Chen, M. Hu, H. Chang, H. Xu, K. F. Ren and J. Ji, J. Mater. Chem. B, 2016, 4, 6358-6365.
4 W. He, Y. Zhang, J. Li, Y. Gao, F. Luo, H. Tan, K. Wang and Q. Fu, Sci. Rep., 2016, 6, 32140.

5 B. Wang, Z. Ye, Y. Tang, Y. Han, Q. Lin, H. Liu, H. Chen and K. Nan, Int. J. Nanomed., 2017, 12, 111-125.

6 A. Tello, B. Austin and T. C. Telfer, Environ. Health Perspect., 2012, 120, 1100-1106.

7 L. Norgrove, Eur. J. Soil Biol., 2007, 43, S303-S310.

8 A. P. Magiorakos, A. Srinivasan, R. B. Carey, Y. Carmeli, M. E. Falagas, C. G. Giske, S. Harbarth, J. F. Hindler, G. Kahlmeter, B. Olsson-Liljequist, D. L. Paterson, L. B. Rice, J. Stelling, M. J. Struelens, A. Vatopoulos, J. T. Weber and D. L. Monnet, Clin. Microbiol. Infect., 2012, 18, 268-281.

9 V. T. H. Pham, V. K. Truong, D. E. Mainwaring, Y. Guo, V. A. Baulin, M. Al Kobaisi, G. Gervinskas, S. Juodkazis, W. R. Zeng, P. P. Doran, R. J. Crawford and E. P. Ivanova, J. Mater. Chem. B, 2014, 2, 2819-2826.

10 G. Yi, Y. Yuan, X. Li and Y. Zhang, Small, 2018, 14, e1703159. 11 E. P. Ivanova, J. Hasan, H. K. Webb, G. Gervinskas, S. Juodkazis, V. K. Truong, A. H. Wu, R. N. Lamb, V. A. Baulin, G. S. Watson, J. A. Watson, D. E. Mainwaring and R. J. Crawford, Nat. Commun., 2013, 4, 2838.

12 L. E. Fisher, Y. Yang, M. F. Yuen, W. Zhang, A. H. Nobbs and B. Su, Biointerphases, 2016, 11, 011014.

13 A. Elbourne, V. E. Coyle, V. K. Truong, Y. M. Sabri, A. E. Kandjani, S. K. Bhargava, E. P. Ivanova and R. J. Crawford, Nanoscale Adv., 2019, 1, 203-212.

14 J. Hasan, H. K. Webb, V. K. Truong, S. Pogodin, V. A. Baulin, G. S. Watson, J. A. Watson, R. J. Crawford and E. P. Ivanova, Appl. Microbiol. Biotechnol., 2013, 97, 9257-9262.

15 E. P. Ivanova, J. Hasan, H. K. Webb, V. K. Truong, G. S. Watson, J. A. Watson, V. A. Baulin, S. Pogodin, J. Y. Wang, M. J. Tobin, C. Lobbe and R. J. Crawford, Small, 2012, 8, 2489-2494.

16 A. Elbourne, R. J. Crawford and E. P. Ivanova, J. Colloid Interface Sci., 2017, 508, 603-616.

17 J. Hasan, R. J. Crawford and E. P. Ivanova, Trends Biotechnol., 2013, 31, 295-304.

18 J. Meng, P. Zhang and S. Wang, Chem.-Asian J., 2014, 9, 2004-2016.

19 A. Tripathy, P. Sen, B. Su and W. H. Briscoe, Adv. Colloid Interface Sci., 2017, 248, 85-104.

20 N. Lin, P. Berton, C. Moraes, R. D. Rogers and N. Tufenkji, Adv. Colloid Interface Sci., 2018, 252, 55-68.

21 K. Nowlin, A. Boseman, A. Covell and D. LaJeunesse, J. R. Soc. Interface, 2015, 12, 20140999.

22 M. N. Dickson, E. I. Liang, L. A. Rodriguez, N. Vollereaux and A. F. Yee, Biointerphases, 2015, 10, 021010.

23 C. D. Bandara, S. Singh, I. O. Afara, A. Wolff, T. Tesfamichael, K. Ostrikov and A. Oloyede, ACS Appl. Mater. Interfaces, 2017, 9, 6746-6760.

24 S. Pogodin, J. Hasan, V. A. Baulin, H. K. Webb, V. K. Truong, T. H. Phong Nguyen, V. Boshkovikj, C. J. Fluke, G. S. Watson, J. A. Watson, R. J. Crawford and E. P. Ivanova, Biophys. J., 2013, 104, 835-840.

25 G. Amy, Desalination, 2008, 231, 44-51. 
26 Z. Cao, L. Mi, J. Mendiola, J. R. Ella-Menye, L. Zhang, H. Xue and S. Jiang, Angew. Chem., Int. Ed. Engl., 2012, 51, 26022605.

27 L. Mi, M. T. Bernards, G. Cheng, Q. Yu and S. Jiang, Biomaterials, 2010, 31, 2919-2925.

28 J. Meng, P. Zhang, F. Zhang, H. Liu, J. Fan, X. Liu, G. Yang, L. Jiang and S. Wang, ACS Nano, 2015, 9, 9284-9291.

29 B. Fang, Y. Jiang, V. M. Rotello, K. Nüsslein and M. M. Santore, ACS Nano, 2014, 8, 1180-1190.

30 H. F. Bohn and W. Federle, Proc. Natl. Acad. Sci. U. S. A., 2004, 101, 14138-14143.

31 L. Gaume, S. Gorb and N. Rowe, New Phytol., 2002, 156, 479489.

32 L. Wang, S. Dong and Q. Zhou, J. Bionic Eng., 2016, 13, 373387.

33 D. S. Luthe, F. Buch, W. E. Kaman, F. J. Bikker, A. Yilamujiang and A. Mithöfer, PLOS ONE, 2015, 10, e0118853.

34 H. Chen, P. Zhang, L. Zhang, H. Liu, Y. Jiang, D. Zhang, Z. Han and L. Jiang, Nature, 2016, 532, 85-89.

35 T. S. Wong, S. H. Kang, S. K. Tang, E. J. Smythe, B. D. Hatton, A. Grinthal and J. Aizenberg, Nature, 2011, 477, 443-447.

36 N. MacCallum, C. Howell, P. Kim, D. Sun, R. Friedlander, J. Ranisau, O. Ahanotu, J. J. Lin, A. Vena, B. Hatton, T.-S. Wong and J. Aizenberg, ACS Biomater. Sci. Eng., 2014, 1, 43-51.

37 J. Chen, C. Howell, C. A. Haller, M. S. Patel, P. Ayala, K. A. Moravec, E. Dai, L. Liu, I. Sotiri, M. Aizenberg, J. Aizenberg and E. L. Chaikof, Biomaterials, 2017, 113, 8092.

38 M. J. Kratochvil, M. A. Welsh, U. Manna, B. J. Ortiz, H. E. Blackwell and D. M. Lynn, ACS Infect. Dis., 2016, 2, 509-517.

39 I. Scholz, M. Buckins, L. Dolge, T. Erlinghagen, A. Weth, F. Hischen, J. Mayer, S. Hoffmann, M. Riederer, M. Riedel and W. Baumgartner, J. Exp. Biol., 2010, 213, 1115-1125.
40 Japanese Industrial Standard: JIS Z 2801: 2000, http:// www.techstreet.com/standards/jis-z-2801-2000? product_id=1233140, accessed: August 2001.

41 H. Peisker and S. N. Gorb, J. Exp. Biol., 2010, 213, 3457-3462. 42 L. Gaume, P. Perret, E. Gorb, S. Gorb, J. J. Labat and N. Rowe, Arthropod Struct. Dev., 2004, 33, 103-111.

43 P. F. Zhang, H. W. Chen and D. Y. Zhang, Journal of Bionic Engineering, 2015, 12, 79-87.

44 X. Duan and D. G. Evans, in Layered Double Hydroxides, Struct. Bond, Springer, 2006, vol. 119, pp. 193-223.

45 J. Liu, X. Huang, Y. Li, K. M. Sulieman, X. He and F. Sun, J. Phys. Chem. B, 2006, 110, 21865-21872.

46 M. A. Djebbi, A. Elabed, Z. Bouaziz, M. Sadiki, S. Elabed, P. Namour, N. Jaffrezic-Renault and A. B. H. Amara, Int. J. Pharm., 2016, 515, 422-430.

47 W.-D. Zhang, Y.-M. Zheng, Y.-S. Xu, Y.-X. Yu, Q.-S. Shi, L. Liu, H. Peng and Y. Ouyang, J. Nanosci. Nanotechnol., 2013, 13, 409-416.

48 S. Ishii, Appl. Entomol. Zool., 1987, 22, 222-228.

49 T. Eisner and D. J. Aneshansley, Proc. Natl. Acad. Sci. U. S. A., 2000, 97, 6568-6573.

50 W. Federle, E. L. Brainerd, T. A. McMahon and B. Holldobler, Proc. Natl. Acad. Sci. U. S. A., 2001, 98, 6215-6220.

51 W. Votsch, G. Nicholson, R. Muller, Y. D. Stierhof, S. Gorb and U. Schwarz, Insect Biochem. Mol. Biol., 2002, 32, 16051613.

52 M. W. England, T. Sato, M. Yagihashi, A. Hozumi, S. N. Gorb and E. V. Gorb, Beilstein J. Nanotechnol., 2016, 7, 1471-1479.

53 A. Peressadko and S. N. Gorb, J. Adhes., 2010, 80, 247-261.

54 E. Gorb and S. Gorb, Entomol. Exp. Appl., 2009, 130, 222-228.

55 J. M. Bullock and W. Federle, J. Exp. Biol., 2009, 212, 18761888.

56 E. Gorb, K. Haas, A. Henrich, S. Enders, N. Barbakadze and S. Gorb, J. Exp. Biol., 2005, 208, 4651-4662.

57 E. V. Gorb, N. Hosoda, C. Miksch and S. N. Gorb, J. R. Soc. Interface, 2010, 7, 1571-1579. 